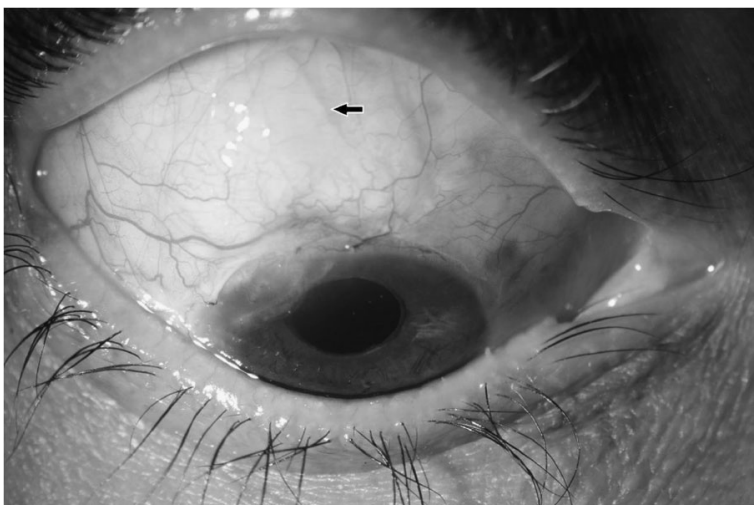

Fig. 2 Patient 1 's right eye post insertion of the pericardium graft superotemporally for reinforcement of sclera prior to Baerveldt (Advanced Medical Optics, Santa Ana, California, USA) tube implantation (black arrow)

transit of the tear film to the lower lid, which increases pooling of commensal organisms near the inferior tube.

Despite a recent survey highlighting glaucoma surgeons preferring trabeculectomies over GDD in advanced glaucoma, they remain contraindicated in scleromalacia patients due to the risk of perforation [5]. The concept of a two-step GDD procedure allowed a safe and effective outcome for recalcitrant glaucoma patients with scleral thinning.

\section{Compliance with ethical standards}

Conflict of interest The authors declare that they have no conflict of interest.

Publisher's note: Springer Nature remains neutral with regard to jurisdictional claims in published maps and institutional affiliations.

\section{References}

1. Marchini G, Ceruti P, Vizzari G, Amantea C, Marchetti P. Longterm outcomes of modified technique using Baerveldt glaucoma implant for the treatment of refractory glaucoma implant for the treatment of refractory glaucoma. J Glaucoma. 2016;25:952-8.

2. Gedde SJ, Schiffman JC, William JF, Leon W, Herndon MD, Brandt JD, et al. Treatment outcomes in tube versus trabeculectomy (TVT) study after 5 years of follow up. Am J Ophthalmol. 2012;153:789-803.

3. Novitskaya ES, Clifford L, Vivian AJ. Tutoplast pericardium patch graft for scleral thinning following strabismus surgery. Eye. 2013;27:682-3.

4. Kwon HJ, Kerr N, Ruddle JB, Ang GS. Endophthalmitis associated with glaucoma shunt intraluminal stent exposure. J Curr Glaucoma Pract. 2016;10:36-37.

5. Rodriguez-Una I, Azuara-Blanco A, King AJ. Survey of glaucoma surgical preferences and post-operative care in the United Kingdom. Clinical Exp Ophthalmol. 2016;45:232-40.

\title{
Intraoperative real-time image-guided ab externo canaloplasty
}

\author{
Rino Frisina ${ }_{(\mathbb{D})}^{1} \cdot$ Alessandro Meduri ${ }^{2}$
}

Received: 30 September 2018 / Revised: 2 February 2019 / Accepted: 20 March 2019 / Published online: 25 April 2019

(C) The Royal College of Ophthalmologists 2019

\section{Introduction}

Real-time image-guided surgery is spreading in different surgical fields for its potential to improve surgical outcome

Rino Frisina

frisinarino@gmail.com

1 Department of Ophthalmology of University of Padova via Giustiniani 2, Padova 35128, Italy

2 Department of Surgical Specialties, Ophthalmology Clinic, University of Messina, Messina 98100, Italy and numerous types of imaging devices are available today [1-5]. The purpose of this study is to evaluate the role of intraoperative ultrasound biomicroscopy (iUBM) and optical coherence tomography (iOCT) for monitoring morphological changes of anterior chamber (AC) structures during ab externo canaloplasty for treating open angle glaucoma (OAG).

\section{Material and methods}

Consecutive patients affected by OAG refractory to topical therapy were enrolled and underwent ab externo 

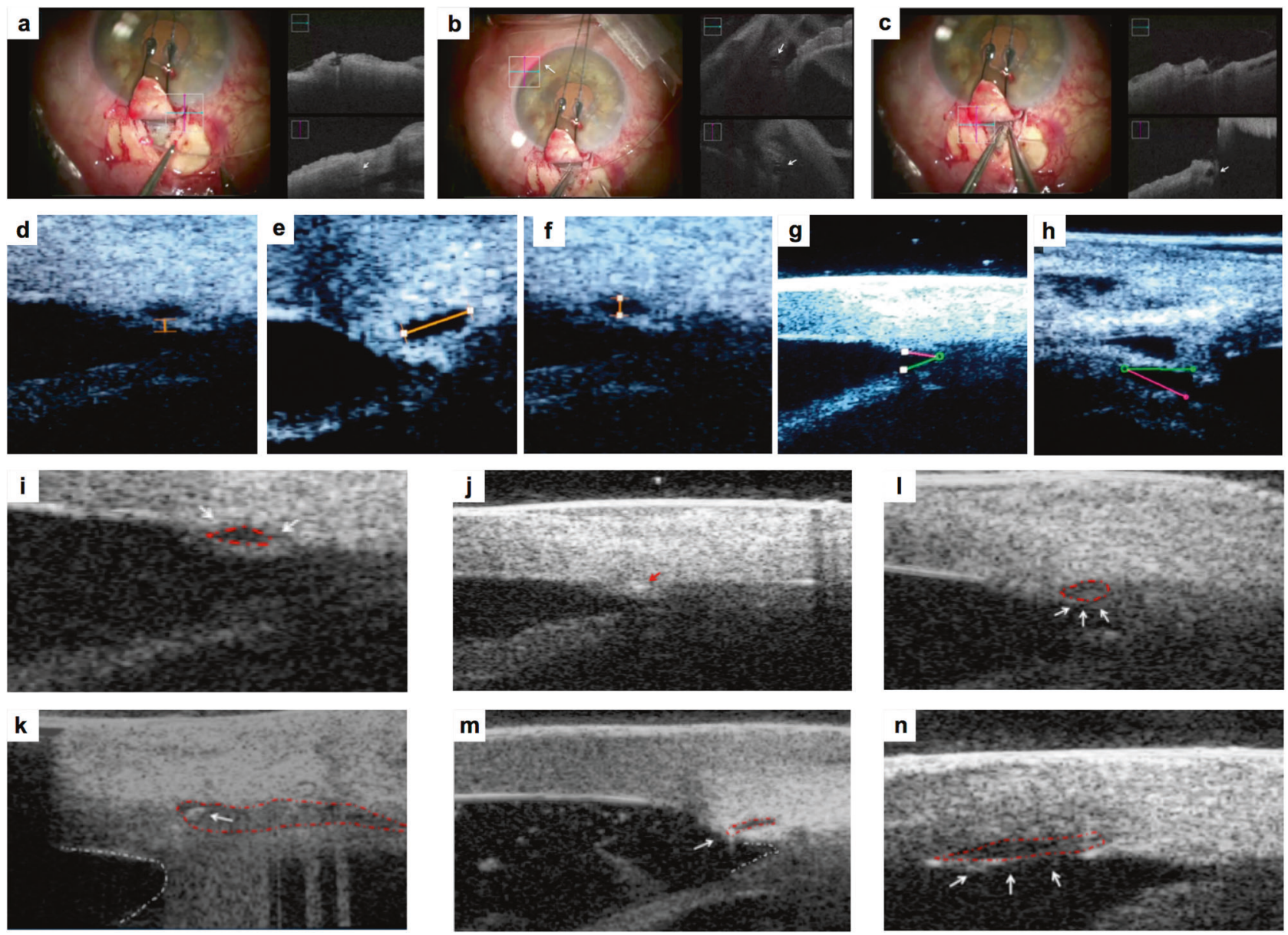

Fig. 1 Picture a Microscope image (left picture) shows trabeculodescemetic window after dissection of the deep scleral flap. iOCT image (right picture) shows SC before dilating the ostium of SC using the iTrack microcatheter (white arrow). Picture b Microscope image (left picture) shows the progress of microcatheter into SC. Red light indicates the position of the microcatheter tip in the SC. iOCT image (right picture) shows the microcatheter in the SC (white arrows) Picture c Microscope imaging shows the final step of retraction of the microcatheter with simultaneous injection of Healon GV into the SC. iOCT image (right picture) shows the enlarged SC (white arrow) Picture d Intraoperative UBM image: TM thickness measurement after SC viscodilation. Picture e, f Intraoperative UBM image: horizontal and vertical diameter of SC after viscodilation. Picture $\mathbf{g}, \mathbf{h}$ Intraoperative UBM image: AC angle before (g) and after surgery (h) Picture i Preoperative iUBM shows SC that appears as an anechogenic oval-shaped space (red dashed line), and TM (white arrow) Picture $\mathbf{j}$ iUBM shows the microcatheter in the SC that appears hyperechogenic in comparison to the surrouding tissue (red arrow) Picture l: iUBM shows enlarged SC after viscodilation (white arrows, red dashed line) Picture k: iUBM shows SC with suture before tensioning suture (white arrow), deep scleral dissection and filtering window (red dashed line). AC angle appears with a concave and rounded profile (white dashed line) Picture $\mathbf{m}$ iUBM shows SC and suture after tensioning suture (white arrow). SC appears elongated (red dashed line) and $\mathrm{AC}$ angle becomes acute (white dashed line) Picture $\mathbf{n}$ iUBM shows Descemet's membrane detachment after viscodilation (white arrows and red dashed line)

Table 1 Demographic and clincal preoperative data of patients

\begin{tabular}{llllllll}
\hline No. & Age (years) & $\begin{array}{l}\text { Gender male } \\
\text { (m)/female (f) }\end{array}$ & IOP, mmHg & $\begin{array}{l}\text { BCVA } \\
\text { logMAR }\end{array}$ & $\begin{array}{l}\text { lens status phakic } \\
\text { (p)/pseudophakic (pp) }\end{array}$ & $\begin{array}{l}\text { AL, mm } \\
\text { type }\end{array}$ \\
\hline 1 & 67 & $\mathrm{f}$ & 34 & 0.6 & $\mathrm{P}$ & 24.7 & POAG \\
2 & 72 & $\mathrm{~m}$ & 36 & 0.5 & $\mathrm{P}$ & 23.5 & POAG \\
3 & 68 & $\mathrm{~m}$ & 26 & 0.8 & $\mathrm{P}$ & 22.8 & POAG \\
4 & 50 & $\mathrm{f}$ & 22 & 0 & $\mathrm{P}$ & 25.8 & POAG \\
5 & 75 & $\mathrm{~m}$ & 31 & 0.1 & $\mathrm{PP}$ & 24.9 & POAG \\
6 & 61 & $\mathrm{~m}$ & 29 & 0.1 & $\mathrm{P}$ & 24 & POAG
\end{tabular}


Table 1 (continued)

\begin{tabular}{|c|c|c|c|c|c|c|c|}
\hline No. & Age (years) & $\begin{array}{l}\text { Gender male } \\
(\mathrm{m}) / \text { female }(\mathrm{f})\end{array}$ & $\mathrm{IOP}, \mathrm{mmHg}$ & $\begin{array}{l}\text { BCVA } \\
\text { logMAR }\end{array}$ & $\begin{array}{l}\text { lens status phakic } \\
\text { (p)/pseudophakic (pp) }\end{array}$ & $\mathrm{AL}, \mathrm{mm}$ & $\begin{array}{l}\text { Glaucoma } \\
\text { type }\end{array}$ \\
\hline 7 & 49 & $\mathrm{f}$ & 29 & 0 & $P$ & 23.7 & POAG \\
\hline 8 & 77 & $\mathrm{~m}$ & 27 & 0 & PP & 22.9 & POAG \\
\hline 9 & 69 & $\mathrm{f}$ & 30 & 0.6 & $\mathrm{P}$ & 23.4 & POAG \\
\hline 10 & 45 & $\mathrm{~m}$ & 24 & 0 & $\mathrm{P}$ & 24.2 & POAG \\
\hline 11 & 71 & $\mathrm{f}$ & 26 & 0 & $\mathrm{PP}$ & 25.4 & POAG \\
\hline 12 & 72 & $\mathrm{~m}$ & 28 & 0.4 & $\mathrm{P}$ & 23.8 & POAG \\
\hline 13 & 69 & $\mathrm{f}$ & 26 & 0.2 & PP & 22.5 & POAG \\
\hline 14 & 49 & $\mathrm{f}$ & 24 & 0 & $\mathrm{P}$ & 22.9 & POAG \\
\hline 15 & 42 & $\mathrm{~m}$ & 31 & 0 & $\mathrm{P}$ & 24.2 & POAG \\
\hline 16 & 51 & $\mathrm{f}$ & 28 & 0 & $\mathrm{P}$ & 25.1 & PEX \\
\hline 17 & 47 & $\mathrm{~m}$ & 26 & 0 & $\mathrm{P}$ & 25.7 & PEX \\
\hline 18 & 58 & $\mathrm{f}$ & 24 & 0 & $\mathrm{P}$ & 22.8 & PG \\
\hline 19 & 46 & $\mathrm{~m}$ & 23 & 0 & $\mathrm{P}$ & 23.1 & PG \\
\hline 20 & 33 & $f$ & 21 & 0 & $\mathrm{P}$ & 24.6 & UG \\
\hline $\begin{array}{l}\text { Total mean } \pm \\
\text { (range) } * \% * *\end{array}$ & $\begin{array}{l}58.5 \pm 12.96 \\
(33-77)\end{array}$ & $50 \% / 50 \%$ & $\begin{array}{l}27.3 \pm 3.9 \\
(21-36)\end{array}$ & $\begin{array}{l}0.14 \pm 0.2 \\
(0.8-0)\end{array}$ & $80 \% / 20 \%$ & $\begin{array}{l}24 \pm 1.02 \\
(22.5-25.8)\end{array}$ & $\begin{array}{l}75 \% / 10 \% / \\
10 \% / 5 \%\end{array}$ \\
\hline
\end{tabular}

$A L$ axial lenght, $B C V A$ best-corrected visual acuity, $I O P$ intraoucular pressure, $P E X$ pseudoespholiative glaucoma, $P G$ pigmentary, $P O A G$ primary open angle glaucomaglaucoma, $U G$ uveitic glaucoma

*Mean \pm (range) for quantitative parameters

*Percentage for qualitative parameters

canaloplasty (iTrack ${ }^{\mathrm{TM}}$, Ellex iScience, Inc., Fremont, CA, USA) between January and June 2017. The study was approved by hospital ethics committee and informed consent from all patients was obtained. Surgery was performed by one surgeon (R.F.). Demographic and preoperative parameters were as follows: age, gender, eye, glaucoma type, intraocular pressure (IOP), best-corrected visual acuity (BCVA), lens status, and axial length. IOP and BCVA were monitored at 1,3 and 6 postoperative months. iOCT integrated on to a microscope (OPMI Lumera 700, RESCAN 700 spectral domain-OCT wavelength $840 \mathrm{~nm}$, Carl Zeiss Meditec, Jena, Germany) and iUBM (iUltrasound iscience interventional ${ }^{\mathrm{TM}}$, Menlo Park CA, 80 megaHertz transducer frequency) were used for evaluating the morphological changes of AC structures and for measuring the diameters of Schlemm canal (SC), trabecular meshwork (TM) thickness and AC angle during the surgery.

\section{Results}

Twenty eyes (20 patients) were recruited (Table 1). IOP decreased significantly during follow-up (from $27.3 \pm 3.9$ to $14.5 \pm 2.5 \mathrm{mmHg}$ ). BCVA improved only in patients who underwent cataract surgery ( 6 out of 20 ).
iOCT allowed the surgeon to monitor SC and AC angle changes during microcatheter passage and viscodilation. During viscodilation SC changed its profile from oval to round-shape with hyporeflective content (Fig. 1a-c). The poor quality of iOCT imaging did not allow the observer to obtain accurate measurements.

TM thickness, SC diameters and AC angle were measured by iUBM. TM thickness mean was $92 \pm 20.6 \mu \mathrm{m}$. Horizontal and vertical diameters mean of SC were, respectively, $410 \pm 56$ and $110 \pm 23 \mu \mathrm{m}$ during viscodilation. AC angle mean was reduced from $25.8^{\circ} \pm 11^{\circ}$ to $24.5^{\circ} \pm 14^{\circ}$ after tensioning suture and its profile changed from concave to acute. SC appeared as an anechogenic oval-shaped space. Microcatheter into SC appeared hyperechogenic. In one case endothelial detachment was detected during viscodilation (Fig. 1d-n).

\section{Discussion}

iOCT allowed the surgeon to monitor morphological changes of $\mathrm{AC}$ structures during surgery but scanning acquisition was not immediate requiring continual adjustment of the focus and scanning point due to the eye movements during surgery that changed the depth of the plan of visualization. The limit of iOCT was the short penetration depth, responsible for 
shadowing of scleral tissue and of overlapping and inverted images. Anyhow, iOCT was the best option to obtain a high resolution for imaging superficial areas. Instead iUBM was useful in detecting deeper structures, giving sharper images to measure morphological changes of AC structures. However, the image acquisition required interrupting surgery and the contact of the probe with the eye.

Intraoperative real-time image-guided surgery represents the future even if it still requires further efforts to make the instrumentation functional and simple to use.

\section{Compliance with ethical standards}

Conflict of interest The authors declare that they have no conflict of interest.

Publisher's note: Springer Nature remains neutral with regard to jurisdictional claims in published maps and institutional affiliations.

\section{References}

1. Li X, Wei L, Dong X, Huang P, Zhang C, He Y, et al. Microscopeintegrated optical coherence tomography for image-aided positioning of glaucoma surgery. J Biomed. 2015;20:76001.

2. Kumar RS, Jariwala MU, V SA, Venugopal JP, Puttaiah NK, Balu R, et al. A pilot study on feasibility and effectiveness of intraoperative spectral-domain optical coherence tomography in glaucoma procedures. Transl Vis Sci Technol. 2015;4:1-9.

3. Yan X, Li M, Chen Z, Zhu Y, Song Y, Zhang H. Schlemm's canal and trabecular meshwork in eyes with primary open angle glaucoma: a comparative study using high-frequency ultrasound biomicroscopy. PLoS One. 2016;4:11.

4. Siebelmann S, Cursiefen C, Lappas A, Dietlein T. Intraoperative optical coherence tomography enables noncontact imaging during canaloplasty. J Glaucoma. 2016;25:236-8.

5. Xj Zhu, Zhang KK, He WW, Sun XH, Meng FR, Lu Y. Diagnosis of pupillary block glaucoma after removal of congenital cataract cataracts with intraoperative ultrasound biomicroscopy: a case report. BMC Ophthalol. 2016;16:58 https://doi.org/10.1186/s12886-016-0238-9.

\title{
Comment on: Pressure and velocity in intraocular and subarachnoid space fluid chambers: an inseparable couple
}

\author{
Joshua P. Harvey (D) ${ }^{1}$ \\ Received: 25 March 2019 / Accepted: 8 April 2019 / Published online: 11 June 2019 \\ (c) The Royal College of Ophthalmologists 2019
}

To the Editor,

I thank Killer et al. for their interesting article regarding the relationship between pressure and velocity, and its implications on aqueous humour turnover [1]. The authors use a combination of the Bernoulli and the Navier-Stokes equations to demonstrate that flow rate of a fluid is a function of both its pressure and velocity. The authors conclude that a high pressure, IOP, results in a lower aqueous velocity. They go onto hypothesise that a low aqueous velocity leads to a reduced turnover of toxic substances in the anterior chamber which likely plays an important role in the pathogenesis of glaucoma. The assumption in their

Joshua P. Harvey

Joshua.harvey@ doctors.org.uk

1 Ophthalmology Department, King's College Hospital, SE5 9RS London, United Kingdom conclusion is that aqueous flow remains constant. If, however, flow were to increase as a function of IOP then velocity may remain constant, or may even increase, thus breaking the inseparable coupling of pressure and velocity alluded to in the authors' title.

The Goldman equation demonstrates that in fact aqueous flow does vary with IOP:

$C=F /\left(\mathrm{IOP}-\mathrm{P}_{\mathrm{e}}\right)$

Rearranged:

$F=C \times\left(\mathrm{IOP}-\mathrm{P}_{\mathrm{e}}\right)$

where $C$ is outflow facility, $F$ is outflow rate and $P_{\mathrm{e}}$ is episcleral venous pressure.

Therefore, as IOP increases, so does the outflow rate. A number of experiments have demonstrated this to be true, and that aqueous flow does not remain constant as the authors have assumed (Fig. 1) [2]. 